\title{
Suicidal Thoughts and Behaviors and Their Associations With Transitional Life Events in Men and Women: Findings From an International Web-Based Sample
}

Alyssa Clare Milton ${ }^{1}$, BSc (Psych), MAppSc (Health Psychology), PhD; Tracey A Davenport ${ }^{1}$, BA (hons), EMBA; Frank Iorfino $^{1}$, BSc( Psych), MBMSc, PhD; Anna Flego ${ }^{2}$, BPT, MPH; Jane M Burns ${ }^{3}$, BA (hons), PhD; Ian B Hickie ${ }^{1}$, AM, MD, FRANZCP, FASSA

\footnotetext{
${ }^{1}$ Brain and Mind Centre, University of Sydney, Camperdown, Australia

${ }^{2}$ The Movember Foundation, Melbourne, Australia

${ }^{3}$ Faculty of Health Sciences, The University of Sydney, Sydney, Australia
}

\section{Corresponding Author:}

Alyssa Clare Milton, BSc (Psych), MAppSc (Health Psychology), PhD

Brain and Mind Centre

University of Sydney

88 Mallet $\mathrm{St}$

Camperdown, 2050

Australia

Phone: 61286276947

Email: alyssa.milton@sydney.edu.au

\section{Abstract}

Background: Although numerous studies have demonstrated sex differences in the prevalence of suicidal thoughts and behaviors (STB), there is a clear lack of research examining the similarities and differences between men and women in terms of the relationship between STB, transitional life events, and the coping strategies employed after experiencing such events when they are perceived as stressful.

Objective: This study aims to examine the differences between men's and women's experiences of STB, sociodemographic predictors of STB, and how coping responses after experiencing a stressful transitional life event predict STB.

Methods: A web-based self-report survey was used to assess the health and well-being of a voluntary community-based sample of men and women aged 16 years and older, living in Australia, Canada, New Zealand, the United Kingdom, and the United States, who were recruited using web-based social media promotion and snowballing.

Results: In total, 10,765 eligible web-based respondents participated. Compared with men, a significantly greater proportion of women reported STB $(P<.001)$ and endorsed experiencing a transitional life event as stressful $(P<.001)$. However, there were no gender differences in reporting that the transitional life event or events was stressful for those who also reported STB. Significant sociodemographic adjusted risk factors of STB included younger age; identifying as a sexual minority; lower subjective social connectedness; lower subjective intimate bonds; experiencing a stressful transitional life event in the past 12 months; living alone (women only); not being in employment, education, or training (women only); suddenly or unexpectedly losing a job (men only); and experiencing a relationship breakdown (men only). Protective factors included starting a new job, retiring, having a language background other than English, and becoming a parent for the first time (men only). The results relating to coping after experiencing a self-reported stressful transitional life event in the past 12 months found that regardless of sex, respondents who reported STB compared with those who did not were less likely to engage in activities that promote social connections, such as talking about their feelings $(P<.001)$. Coping strategies significantly explained $19.0 \%$ of the STB variance for men $\left(F_{16,1027}=14.64 ; P<.001\right)$ and $22.0 \%$ for women $\left(F_{16,1977}=36.45 ; P<.001\right)$.

Conclusions: This research highlights multiple risk factors for STB, one of which includes experiencing at least one stressful transitional life event in the past 12 months. When individuals are experiencing such events, support from services and the community alike should consider using sex-specific or targeted strategies, as this research indicates that compared with women, more men do nothing when experiencing stress after a transitional life event and may be waiting until they experience STB to engage with their social networks for support. 
(JMIR Ment Health 2020;7(9):e18383) doi: 10.2196/18383

\section{KEYWORDS}

suicidal ideation; suicide; suicide, attempted; men; women; sex differences; life change events; adaptation, psychological; health surveys

\section{Introduction}

\section{Background}

Despite a considerable increase in global efforts to address suicidal thoughts and behaviors (STB), a corresponding decrease in the prevalence of death by suicide has not been observed [1]. STB are strong predictors of suicide deaths [2], contributing to substantial disability among individuals and having broader impacts on the individual's social networks and the wider economy [3-5]. Suicide continues to be a significant public health concern [6], and improving our understanding of the factors associated with STB to mitigate risk, enhance health promoting behaviors, and evolve current support systems is clearly an ongoing need.

Men die by suicide significantly more frequently than women $[7,8]$, although lifetime STB are higher among women than men [9]. This gender paradox is even more pronounced in high-income countries [8]. Furthermore, men in their middle years are at one of the highest risks for suicide in English-speaking, high-income countries such as Australia, Canada, the United Kingdom, and the United States [10-13].

Suicide and its relationship to transitional life events during adulthood is starting to receive increased attention in the literature [6,14]. A systematic review by Lui and Miller [6] found evidence of an association between negative life events, which they define as life stressors, and STB. Transitional life events can relate to one's stage of development (such as retirement), historical events (such as war), and idiosyncratic factors (such as a change in an individual's health status) [15]. To date, however, there has been an insufficient level of international research examining how transitional life events relating to different life stages predict STB in both men and women. This may be important, as such transitional life events can initiate a shift in the purpose and the direction of life [15], and unsuccessful transitions at certain stages may be associated with higher levels of psychological vulnerability. Indeed, transitional life events have the potential to impact individuals differently, with some individuals perceiving them as stressful (ie, a negative life event) and some not.

During transitional life events, an individual needs to use coping strategies, which can be adaptive or maladaptive, to adapt to the new stage in life $[16,17]$. In brief, maladaptive coping has been referred to as dysfunctional, regressive, or avoidant coping in the literature [18]. For example, Zuckerman and Gagne [19] highlight that maladaptive coping can involve disengagement, denial, blame, or self-punishment. It is hypothesized that these are key risk factors for STB. Adaptive coping, on the other hand, has often been defined as functional, transformative, or approach focused, where individuals use coping strategies such as problem solving, help seeking, and emotional expression in response to stressors [18]. Interestingly, a meta-analysis by Tamres et al
[20] reported sex differences in coping, with women predominantly engaging in more adaptive or expressive types of coping strategies. How an individual copes (ie, in adaptive or maladaptive ways) if they perceive the life event as stressful may also be associated with STB. However, to our knowledge, comparing both adaptive and maladaptive coping strategies of men and women who have, or have not, experienced STB after experiencing a transitional life event has not been studied.

\section{Objectives}

This substudy analyzes data collected in an international research project, the Global Health \& Wellbeing Survey [21,22], and provides a unique opportunity to explore, on a larger scale, men's and women's experiences of STB and their associations - with a particular focus on transitional life events, how these events are perceived, and how an individual copes when experiencing these events.

The aims of this substudy are to assess (1) the differences between men and women in their experience of STB, transitional life events, and their perception of the event in the past 12 months; (2) the sociodemographic (including demographics, social connections, and transitional life events) predictors of STB in the past 12 months for men and women; and (3) the sex differences in the methods of coping with stressful transitional life events for those who have experienced STB compared with those who have not.

\section{Methods}

\section{Design}

A web-based survey methodology was used to assess the views of a voluntary community sample living in 5 target countries, including Australia, Canada, New Zealand, the United Kingdom, and the United States.

\section{Participants}

The survey sample included men and women (aged 16 years and older) who reported that they had lived in 1 of the 5 target countries for the best part of the past 12 months.

\section{Procedure}

The primary study received institutional ethics approval from the University of Sydney's Human Research Ethics Committee (protocol number 2015/412). The open survey was tested before being hosted on the web from July 1, 2015, to December 11, 2015. A web-based advertising methodology was used to recruit respondents in the 5 target countries. Several strategies were used for survey dissemination and recruitment, including using multiple social media channels (eg, Facebook, Twitter, YouTube, and Instagram) [23]; layering of recruitment messages [24]; and passive snowballing via social media to spread study information through sharing, liking, and tweeting [23,25]. Both paid (via Facebook and YouTube, with budget set at Aus \$10 
[US \$7.6] per participant, maximum spend of Aus $\$ 100,000$ [US \$76,400]) and free social media advertising (via a Facebook page, Twitter, and Instagram) were used. Recruitment targeting, based on age, sex, and region, was carried out through paid Facebook advertising channels to increase responses from harder-to-reach groups. This approach was supplemented by a traditional snowballing technique [26], in which respondents and wider networks forwarded the study to others. Respondents gave consent through the web and understood that they could cease participation at any time and that their responses were confidential and nonidentifiable. No incentives to participate were provided. Depending on participant answers, the survey took between 20 and 45 min to complete.

\section{Measures}

Items in this substudy were extracted from the full Global Health $\&$ Wellbeing Survey. The number of questions completed by each participant varied depending on the skip pattern. The following are the areas of interest specific to this substudy: demographics, social connectedness, transitional life events, and STB.

\section{Demographics}

Demographic items included sex (response options: men vs women); age (responses collapsed into age groups 16-24 years, 25-44 years, $45-64$ years, and $\geq 65$ years); language background (language background other than English [LBOTE] vs English); living in a rural or remote location (responses collapsed into yes vs no); living arrangement (living alone vs not living alone); employment, education, and training status (responses collapsed into not in education, employment, or training [NEET] vs in education, employment, or training [EET]); and sexual orientation (responses collapsed into heterosexual vs lesbian, gay, bisexual, transsexual, queer, intersex, or asexual [LGBTQIA]).

\section{Social Connectedness}

Perceived social support and conflict in close relationships were measured by the 5-item Schuster's Social Support and Conflict Scale [27] (Cronbach $\alpha=.71 ; n=8139$ ). The 12 items on the care dimension of the Intimate Bond Measure [28] were used as an indicator of perceived care from one's partner (Cronbach $\alpha=.96$; $\mathrm{n}=8102$ ).

\section{Transitional Life Events}

Respondents indicated whether or not they had experienced any of 7 specific transitional life events over the past 12 months, including finishing high school or secondary school, starting university or college, starting a new job, becoming a parent for the first time, suddenly or unexpectedly becoming unemployed, relationship breakdown, and retiring. Those who affirmed they had experienced one of these events were asked whether they found this experience stressful (yes or no). If yes, respondents were asked about their coping strategies. Items included a range of adaptive and maladaptive coping strategies (eg, get professional help or become aggressive).

\section{$S T B$}

Respondents' level of suicidality over the past 12 months was measured using the suicidal thoughts and acts subscale from the Psychiatric Symptom Frequency Scale (PSFS) [29], which was originally developed in the United Kingdom and has been used in both Australia and North America [30-33]. The subscale consists of 5 items concerning suicidal thoughts and acts that are each presented with dichotomous response options (yes and no). From the subscale, we can infer 4 different areas of suicidality: (1) suicidal thoughts, a desire to end one's life without a specific plan; (2) suicide plans, formulating a strategy to end one's life; (3) suicide attempts, nonfatal self-injurious behavior that includes some intent to end one's life; and (4) STBs, the combination of an individual engaging in suicidal thoughts, plans, and/or attempts (Cronbach $\alpha=.82 ; \mathrm{n}=8705$ ).

\section{Analysis}

Survey data were prepared and analyzed using IBM SPSS Statistics for Windows, version 22.0 (2013; IBM Corp). A 95\% confidence level was used across all the analyses.

Chi-square tests were conducted to assess for significant differences between men and women in their experience of STB and transitional life events in the past 12 months (aim 1). Subsequently, Cramer V was calculated to determine the strength of the association. To adjust for type 1 error, a Holm-Bonferroni correction was applied.

Owing to the significant gender differences highlighted in aim 1,2 logistic regression analyses (separately for men and women) were conducted to address aim 2. Following previously established procedures [34], 2 logistic regressions were run separately for men and women to identify sociodemographic (including demographics, social connectedness, specific transitional life events experienced in the past 12 months, and whether these life events were perceived as stressful) predictors of STB based on the PSFS.

To address aim 3, additional chi-square and Cramer V analyses were conducted to compare sex differences in coping after experiencing transitional life events for those who have experienced STB with those who have not (aim 3). For all analyses, no missing data were imputed, and $95 \%$ confidence levels were used. Again, a Holm-Bonferroni correction was applied to adjust for type 1 error. Owing to the noted sex differences, 2 additional linear regression analyses were used to examine the association between coping items and STB by sex. Missing data were excluded listwise. Regression model assumptions of linearity, homoscedasticity, independence, and normality (evaluated using standard residual-based diagnostic procedures) were met, with collinearity estimates among variables in both models being acceptable (tolerance $>0.40$; Durbin Watson >1.0).

\section{Ethical Standards}

The authors assert that all procedures that contributed to this work complied with the ethical standards of the relevant national and institutional committees on human experimentation and with the Helsinki Declaration of 1975, as revised in 2008. 


\section{Results}

\section{Respondent Participation Rates and Characteristics}

A total of 16,510 people were presented with the consent and eligibility screen. Of these, the total eligible sample was 10,765 respondents $(10,765 / 16,510,65.20 \%)$. Of those excluded, $75.30 \%$ (4326/5745) did not provide consent to participate and $12.36 \%(710 / 5745)$ were aged younger than 16 years.

In total, $31.11 \%(3349 / 10,765)$ of eligible participants were from Australia, followed by $18.00 \%(1938 / 10,765)$ from the United Kingdom, $17.54 \%$ (1888/10,765) from Canada, 17.07\% $(1838 / 10,765)$ from the United States, and $16.27 \%$ $(1752 / 10,765)$ from New Zealand. The majority of the participants were women $(6464 / 10,765,60.05 \%)$, aged 45 to 64 years $(3625 / 10,753,33.71 \%)$, not living in rural or remote areas $(6787 / 10,703,63.41 \%)$, living with others $(5781 / 7115$, $81.25 \%)$, heterosexual $(5923 / 7116,83.23 \%)$, from an English-speaking background $(5971 / 7484,79.78 \%)$, and in paid EET (7220/9998, 72.21\%). The details of participant characteristics are presented in Table 1, and a detailed breakdown of sociodemographic variables by sex and country are presented in Multimedia Appendices 1 and 2, respectively. Of the respondents who experienced at least one transitional life event in the past 12 months, 70.48\% (3142/4458) reported that it was stressful.

\section{STB and Stressful Transitional Life Events}

In the past 12 months, almost one-fourth of respondents in the full sample reported thinking about taking their own lives
(2071/8708, 23.78\%), 7.81\% (680/8708) had made plans, and $3.03 \%(264 / 8708)$ had attempted to take their own life. Compared with men, a significantly greater proportion of women reported experiencing each of the PSFS items, including attempts $(P \leq .001)$, plans $(P \leq .001)$, and thoughts $(P=.01)$. A large effect size (Cramer $\mathrm{V} \geq 0.05$ ) was seen for the item attempted to take your own life. All $P$ values remained at the same level of significance after a Holm-Bonferroni correction was applied (see Multimedia Appendix 3 for a full breakdown of the PSFS results).

The frequency statistics of respondents' experience of a major life event or events in the past 12 months and their responses are presented in Table 2 and address aim 1. About half $(4450 / 9029,49.29 \%)$ of all respondents experienced at least one of the 7 presented major life events. Of the respondents who experienced at least one major life event in the past 12 months, $70.45 \%$ (3135/4450) reported that it was stressful. Women were significantly more likely than men to endorse experiencing the major life event or events as stressful $(P<.001)$. In total, $84.40 \%(1390 / 1647)$ of the respondents who had also experienced STB in the past 12 months reported the major life event or events as stressful. These results were not statistically different between genders. When considering people who had experienced at least one major life event in the past 12 months but reported no suicidal thoughts, significantly more women felt the major life event or events was stressful (women $65.58 \%$ [1069/1630] vs men 55.4\% [546/986]; $P<.001)$. All results remained the same after applying the Holm-Bonferroni correction. 
Table 1. Participants' sociodemographics by sex.

\begin{tabular}{|c|c|}
\hline Variable & Full sample \\
\hline \multicolumn{2}{|l|}{$\operatorname{Sex}(N=10,765), n(\%)$} \\
\hline Male & $4301(39.95)$ \\
\hline Female & $6464(60.05)$ \\
\hline \multicolumn{2}{|l|}{ Age (years; $n=10,753), n(\%)$} \\
\hline $16-24$ & $2690(24.99)$ \\
\hline $25-44$ & $2444(22.71)$ \\
\hline $45-64$ & $3625(33.68)$ \\
\hline$\geq 65$ & $1994(18.53)$ \\
\hline \multicolumn{2}{|l|}{ Rural or remote $(\mathrm{n}=10,703), \mathrm{n}(\%)$} \\
\hline No & $9990(93.34)$ \\
\hline Yes & $713(6.66)$ \\
\hline \multicolumn{2}{|l|}{ EET $^{\mathrm{a}}$ status $(\mathrm{n}=9998), \mathrm{n}(\%)$} \\
\hline No (not in education, employment, or training) & $2778(27.79)$ \\
\hline Yes (EET) & $7220(72.21)$ \\
\hline \multicolumn{2}{|l|}{ Living arrangements $(\mathrm{n}=7115), \mathrm{n}(\%)$} \\
\hline Live with others & $5781(81.25)$ \\
\hline Live alone & $1334(18.75)$ \\
\hline \multicolumn{2}{|l|}{ Language background (n=7484), n (\%) } \\
\hline English & $5971(79.78)$ \\
\hline Language background other than English & $1513(20.22)$ \\
\hline \multicolumn{2}{|l|}{ Sexual orientation $(n=7116), n(\%)$} \\
\hline Heterosexual & $5923(83.23)$ \\
\hline Lesbian, gay, bisexual, transsexual, queer, intersex, or asexual & $1193(16.77)$ \\
\hline \multicolumn{2}{|l|}{ Social connectedness, mean (SD) } \\
\hline Intimate bonds $(\mathrm{n}=8102)$ & $25.5(9.5)$ \\
\hline Social support $(\mathrm{n}=8139)$ & $9.3(2.7)$ \\
\hline \multicolumn{2}{|l|}{ Transitional life event (yes), n (\%) } \\
\hline Became a parent for the first time $(n=9035)$ & $145(1.60)$ \\
\hline Finished high school or secondary school $(\mathrm{n}=9034)$ & $606(6.71)$ \\
\hline Started university or college $(\mathrm{n}=9032)$ & $799(8.85)$ \\
\hline Started a new job $(n=9037)$ & $2153(23.82)$ \\
\hline Suddenly or unexpectedly become unemployed ( $\mathrm{n}=9033)$ & $793(8.77)$ \\
\hline Retired $(n=9034)$ & $598(6.62)$ \\
\hline Relationship breakdown $(\mathrm{n}=9034)$ & $2073(22.95)$ \\
\hline Transitional life event perceived as stressful $(n=4458)$ & $3142(70.48)$ \\
\hline
\end{tabular}

${ }^{a}$ EET: education, employment, or training. 
Table 2. Frequency and experience of major life events, stress responses, and suicidal thoughts and behaviors.

\begin{tabular}{|c|c|c|c|c|c|c|c|}
\hline \multirow[t]{2}{*}{ Response } & \multirow{2}{*}{$\begin{array}{l}\text { Total sample, } \mathrm{n} \\
(\%)\end{array}$} & \multirow[t]{2}{*}{ Men, n (\%) } & \multirow[t]{2}{*}{ Women, $\mathrm{n}(\%)$} & \multicolumn{4}{|c|}{ Men versus women } \\
\hline & & & & $\begin{array}{l}\text { Chi-square } \\
(d f)\end{array}$ & $P$ value & Cramer V & $\begin{array}{l}\text { Holm-Bonferroni } \\
\text { correction }\end{array}$ \\
\hline \multicolumn{8}{|c|}{ Experienced a major life event } \\
\hline No & $4579(50.71)$ & $1995(43.57)$ & $1633(36.70)$ & $44.3(1)$ & $<.001$ & 0.07 & $<.001$ \\
\hline Yes & $4450(49.29)$ & $2584(56.12)$ & $2817(63.30)$ & $44.3(1)$ & $<.001$ & 0.07 & $<.001$ \\
\hline \multicolumn{8}{|c|}{ If yes, did you find this experiences stressful? } \\
\hline No & $1315(29.55)$ & $563(34.48)$ & $752(26.70)$ & $30.1(1)$ & $<.001$ & 0.08 & $<.001$ \\
\hline Yes & $3135(70.45)$ & $1070(65.52)$ & $2065(73.30)$ & $30.1(1)$ & $<.001$ & 0.08 & $<.001$ \\
\hline \multicolumn{8}{|c|}{ Suicidal thoughts and behaviors (past 12 months) } \\
\hline Stressful experience & $1390(84.40)$ & $471(84.11)$ & $920(84.56)$ & $0.1(1)$ & .80 & 0.01 & .80 \\
\hline Experience not stressful & $257(15.60)$ & $89(15.89)$ & $168(15.44)$ & $0.1(1)$ & .80 & 0.01 & .80 \\
\hline \multicolumn{8}{|c|}{ No suicidal thoughts and behaviors (past 12 months) } \\
\hline Stressful experience & $1630(62.31)$ & $561(56.04)$ & $1069(66.19)$ & $27.1(1)$ & $<.001$ & 0.10 & $<.001$ \\
\hline Experience not stressful & $986(37.69)$ & $440(43.96)$ & $546(33.81)$ & $27.1(1)$ & $<.001$ & 0.10 & $<.001$ \\
\hline
\end{tabular}

\section{Predictors of STB}

Adjusted odds ratios (AORs) and 95\% CIs for the 2 subsamples (men and women) are presented in Table 3 (see Multimedia Appendix 4 results, including unadjusted risk ratios) and address aim 2. The models explained $24.0 \%$ and $31.0 \%$ of the variance for men and women, respectively (Nagelkerke $R^{2}$ men $=0.24$; Nagelkerke $R^{2}$ women=0.31).

The results presented in Table 3 show that men and women shared some similarities in relation to sociodemographic risks of STB. Specifically, those in younger age groups, particularly those aged 16 to 24 years compared with those aged 65 years or older (men: 16-24 years; AOR 2.89, 95\% CI 1.96-4.26; $P<.001$ and women: $16-24$ years; AOR 4.03, 95\% CI 2.78-5.85; $P<.001$ ), those who identified as LGBTQIA (men: AOR 1.96, 95\% CI 1.56-2.46; $P<.001$ and women: AOR 3.01, 95\% CI $2.45-3.71 ; P<.001)$, and those who perceived a transitional life event they experienced in the past 12 months as stressful (men: AOR 1.38, 95\% CI 1.15-1.67; $P=.001$ and women: AOR 1.55, $95 \%$ CI 1.34-1.79; $P<.001$ ), had significantly elevated AOR of STB. For men, significantly higher AOR of STB were observed for those who experienced a relationship breakdown (AOR 1.45, 95\% CI 1.06-1.98; $P=.02$ ) and those who suddenly or unexpectedly became unemployed (AOR 1.63, 95\% CI $1.16-2.29 ; P=.005)$. For women, identifying as NEET (AOR $1.67,95 \%$ CI 1.31-2.15; $P<.001$ ) and living alone (AOR 1.38, $95 \%$ CI $1.11-1.71 ; P=.004)$ were associated with increased AOR of STB.

When considering protective factors, men and women had similar findings. Specifically both men and women had significantly lower AOR of STB if they identified as having a LBOTE (men: AOR 0.67, 95\% CI 0.51-0.88; $P=.004$ and women: AOR $0.64,95 \%$ CI $0.51-0.80 ; P<.001)$, reported higher levels of satisfaction with their social support (men: AOR 0.87, 95\% CI 0.83-0.90; $P<.001$ and women: AOR 0.78, 95\% CI $0.75-0.81 ; P<.001)$, higher intimate bonds ratings (men: AOR $0.96,95 \%$ CI $0.95-0.98 ; P<.001$ and women: AOR $0.98,95 \%$ CI $0.97-0.99 ; P<.001$ ), started a new job (men: AOR 0.73, $95 \%$ CI $0.55-0.97 ; P=.02$ and women: AOR 0.80, 95\% CI 0.65-1.00; $P=.049$ ), or retired (men: AOR $0.52,95 \%$ CI $0.33-0.82 ; P=.004$ and women: AOR $0.44,95 \%$ CI $0.29-0.68 ; P<.001)$. Men who became a parent for the first time in the past 12 months had lower AOR of STB (AOR 0.30, 95\% CI 0.10-0.86; $P=.026$ ). 
Table 3. Adjusted odds ratios for men's and women's self-reported suicidal thoughts and behaviors by sociodemographic variables, including social connections and transitional life events (men, n=2667 and women, $n=3826$ ).

Participant characteristics

Suicidal thoughts and behaviors (Psychiatric Symptom Frequency Scale), adjusted odds ratio $(95 \% \mathrm{CI})^{\mathrm{a}}$

Men

Women

\section{Sociodemographics}

Age bands (years) versus $\geq 65$

16-24

$25-44$

45-64

$\geq 65$

Rural

Yes

No

\section{Sexual orientation}

Lesbian, gay, bisexual, trans, queer, intersex, or asexual

Heterosexual

\section{Language background other than English}

Yes

No

\section{EET $^{\mathbf{c}}$}

No (not in education, employment, or training)

Yes (EET)

\section{Living arrangements}

Live alone

Live with others

Social connectedness

Intimate bonds

Social support

\section{Transitional life events}

Became a parent for the first time

Finished high school or secondary school

Started university or college

Started a new job

Suddenly or unexpectedly become unemployed

Retired

Relationship breakdown

Transitional life event perceived as stressful

$$
\begin{aligned}
& 2.89(1.96-4.26)^{\mathrm{b}} \\
& 1.97(1.38-2.80)^{\mathrm{b}} \\
& 1.96(1.46-2.64)^{\mathrm{b}} \\
& 1.00(1.00-1.00)
\end{aligned}
$$

$1.04(0.72-1.50)$

$1.35(0.98-1.85)$

$1.00(1.00-1.00)$

$1.00(1.00-1.00)$

$1.96(1.56-2.46)^{\mathrm{b}}$

$1.00(1.00-1.00)$

$3.01(2.45-3.71)^{b}$

$1.00(1.00-1.00)$

$0.67(0.51-0.88)^{\mathrm{b}}$

$1.00(1.00-1.00)$

$0.64(0.51-0.80)^{\mathrm{b}}$

$1.00(1.00-1.00)$

$1.27(0.98-1.63)$

$1.00(1.00-1.00)$

$1.67(1.31-2.15)^{\mathrm{b}}$

$1.00(1.00-1.00)$

$1.27(0.99-1.61)$

$1.00(1.00-1.00)$

$1.38(1.11-1.71)^{\mathrm{b}}$

$1.00(1.00-1.00)$

$\begin{array}{ll}0.96(0.95-0.98)^{\mathrm{b}} & 0.98(0.97-0.99)^{\mathrm{b}} \\ 0.87(0.83-0.90)^{\mathrm{b}} & 0.78(0.75-0.81)^{\mathrm{b}}\end{array}$

$0.30(0.10-0.86)^{\mathrm{d}}$

$0.66(0.31-1.41)$

$1.07(0.65-1.77)$

$0.96(0.69-1.33)$

$0.81(0.54-1.21)$

$0.83(0.62-1.10)$

$0.73(0.55-0.97)^{\mathrm{d}}$

$0.80(0.65-1.00)^{\mathrm{d}}$

$1.63(1.16-2.29)^{\mathrm{b}}$

$1.24(0.93-1.66)$

$0.52(0.33-0.82)^{\mathrm{b}}$

$0.44(0.29-0.68)^{\mathrm{b}}$

$1.45(1.06-1.98)^{\mathrm{d}}$

$0.93(0.73-1.18)$

$1.38(1.15-1.67)^{\mathrm{b}}$

\footnotetext{
${ }^{a}$ Adjusted for all variables.

${ }^{\mathrm{b}}$ Significant at $99 \%$ confidence level.

${ }^{c}$ EET: education, employment, or training.
} 
${ }^{\mathrm{d}}$ Significant at $95 \%$ confidence level.

\section{Coping After Experiencing a Stressful Life Event}

There were 5 areas consistently identified by respondents as top coping strategies, irrespective of gender. These included sleeping too much or too little $(2279 / 3130,72.81 \%$ of all respondents), talking to someone about their feelings $(2177 / 3132,69.51 \%$ of all respondents), eating more or eating less (2069/3130, $66.10 \%$ of all respondents), isolating themselves (1795/3138, 57.20\% of all respondents), and talking to someone for advice (1790/3129, 57.21\% of all respondents). Table 4 presents further frequency data relating to men's and women's coping responses after experiencing a transitional life event perceived as stressful by self-reported STB in the past 12 months.

Table 4. Frequency of men's and women's coping responses after experiencing a stressful transitional life event for participants who did and did not report suicidal thoughts and behaviors.

\begin{tabular}{|c|c|c|c|c|}
\hline \multirow[t]{3}{*}{ Response based on stressful life experience } & \multicolumn{4}{|c|}{ Suicidal thoughts and behaviors (Psychiatric Symptom Frequency Scale) } \\
\hline & \multicolumn{2}{|l|}{ Men } & \multicolumn{2}{|l|}{ Women } \\
\hline & No & Yes & No & Yes \\
\hline Sample size, range & $561-563$ & $467-471$ & $1063-1071$ & 916-919 \\
\hline Became aggressive ( $\%$ yes) & 14.59 & 27.66 & 8.71 & 19.28 \\
\hline Bossy or inflexible or angry (\% yes) & 28.29 & 37.58 & 29.78 & 43.96 \\
\hline Eat more or less (\% yes) & 47.51 & 66.81 & 62.90 & 80.07 \\
\hline Engage in spiritual activity (\% yes) & 31.49 & 27.66 & 32.02 & 30.50 \\
\hline Got professional help (\% yes) & 25.09 & 47.66 & 23.20 & 46.90 \\
\hline Increased tobacco or alcohol or drugs (\% yes) & 26.82 & 43.31 & 20.02 & 37.11 \\
\hline Isolated self (\% yes) & 43.59 & 75.16 & 40.24 & 76.17 \\
\hline Overdo activities (\% yes) & 20.28 & 25.32 & 26.29 & 32.86 \\
\hline Sleep too much or too little (\% yes) & 60.85 & 80.64 & 65.29 & 84.31 \\
\hline Spend time with friends or loved ones ( $\%$ yes) & 32.74 & 22.51 & 39.70 & 25.16 \\
\hline Work less or more (\% yes) & 31.32 & 42.34 & 27.81 & 46.51 \\
\hline Take more risks (\% yes) & 20.82 & 35.46 & 14.41 & 29.27 \\
\hline Talk to someone about feelings ( $\%$ yes) & 64.48 & 66.38 & 75.51 & 67.14 \\
\hline Talk to someone for advice (\% yes) & 50.36 & 56.60 & 59.31 & 59.37 \\
\hline Do nothing (\% yes) & 23.67 & 33.05 & 17.57 & 33.33 \\
\hline Other (\% yes) & 13.01 & 16.70 & 12.32 & 18.45 \\
\hline
\end{tabular}

An in-depth chi-square and Cramer $\mathrm{V}$ analyses using a Bonferroni correction, addressing aim 3, showed that there were multiple sex differences in coping after experiencing a transitional life event that was perceived by the individual as stressful (see Multimedia Appendix 5 for a full breakdown of results). Regardless of whether a respondent experienced STB in the past 12 months or not, women reported significantly higher rates of eating more or eating less (no STB: $62.90 \%$ [women] vs $47.51 \%$ [men]; $P<.001$ and STB: $80.07 \%$ [women] vs $66.81 \%$ [men]; $P<.001)$ and lower rates of overdoing activities (no STB: $26.29 \%$ [women] vs $20.28 \%$ [men]; $P<.01$ and STB: $32.86 \%$ [women] vs $25.32 \%$ [men]; $P<.01$ ). Conversely, compared with women, men reported significantly higher rates of becoming aggressive (no STB: $8.71 \%$ [women] vs $14.59 \%$ [men]; $P<.001$ and STB: $19.28 \%$ [women] vs $27.66 \%$ [men]; $P<.001$ ); taking more risks (no STB: $14.41 \%$ [women] vs $20.82 \%$ [men]; $P<.01$ and STB: $29.27 \%$ [women] vs $35.46 \%$ [men]; $P=.02$ ); and increasing their use of tobacco, alcohol, or other drugs (no STB: $20.02 \%$ [women] vs $26.82 \%$ [men]; $P<.01$ and STB: $37.11 \%$ [women] vs $43.31 \%$ [men]; $P=.03)$. Of these, eating more or eating less and becoming aggressive remained significant after adjusting for multiple comparisons using a Bonferroni correction.

For those who did not experience STB, women reported significantly higher rates of talking to someone about their feelings ( $75.51 \%$ [women] vs $64.48 \%$ [men]; $P<.001$ ), spending more time with friends and loved ones (39.70\% [women] vs $32.74 \%$ [men]; $P<.01$ ), and talking to someone for advice (59.31\% [women] vs 50.36\% [men]; $P<.01)$; however, there were no differences between men and women for these variables if the respondent had also experienced STB in the past 12 months. Finally, men reported higher rates of doing nothing (17.57\% [women] vs $23.67 \%$ [men]; $P<.01)$ when they had not experienced STB in the past 12 months; however, there were no differences between men and women for this variable if respondents did experience STB.

When comparing all participant's coping responses after experiencing a transitional life event that was perceived as stressful, the respondents who did report STB were significantly 
more likely to engage in detrimental activities such as becoming aggressive (22.10\% [STB] vs $10.74 \%$ [no STB]; $P<.001)$; becoming bossy or inflexible or angry with others $(41.80 \%$ [STB] vs $29.26 \%$ [no STB]; $P<.001$ ); eating more or eating less $(75.58 \%$ [STB] vs $57.60 \%$ [no STB]; $P<.001)$; increasing their use of tobacco, alcohol, or other drugs (39.21\% [STB] vs $22.37 \%$ [no STB]; $P<.001)$; isolating themselves (75.83\% [STB] vs $41.40 \%$ [no STB]; $P<.001)$; overdoing activities $(30.31 \%$ [STB] vs $24.22 \%$ [no STB]; $P<.001)$; sleeping too much or too little $(83.07 \%$ [STB] vs $63.76 \%$ [no STB]; $P<.001)$; working more or working less $(45.10 \%$ [STB] vs $29.02 \%$ [no STB]; $P<.001)$; taking more risks (31.37\% [STB] vs $16.62 \%$ [no STB]; $P<.001)$; and doing nothing (33.24\% [STB] vs $19.67 \%$ [no STB]; $P<.001)$. Furthermore, this group was significantly less likely to engage in the potentially helpful activities of spending more time with friends and loved ones (24.26\% [STB] vs $37.30 \%$ [no STB]; $P<.001)$ and talking to someone about their feelings $(66.88 \%$ [STB] vs $71.71 \%$ [no STB]; $P<.01)$. However, they were also significantly more likely to get professional help (47.16\% [STB] vs $23.85 \%$ [no STB]; $P<.001)$.

Table 5 shows 2 linear regression models, which present data on how the different types of coping strategies (after experiencing a transitional life event perceived as stressful) explained the variance in STB for men and women (aim 3). For men, the regression model significantly explained $19.0 \%$ of the variance in STB $\left(F_{16,1027}=14.64 ; P<.001 ; R^{2}\right.$ adjusted=0.19), with 7 variables accounting for this variance at a $95 \%$ confidence level. In order of effect size, this included isolating self $(\beta=.21 ; P<.001)$, getting professional help $(\beta=.20 ; P<.001)$, doing nothing $(\beta=.09 ; P=.004)$, becoming aggressive $(\beta=.09$; $P=.004)$, sleeping too much or too little $(\beta=.09 ; P=.005)$, increasing alcohol and other drug use $(\beta=.06 ; P=.036)$, and other $(\beta=.06 ; P=.048)$. For women, the regression model significantly explained $22.0 \%$ of the variance in STB $\left(F_{16,1977}=36.45 ; P<.001 ; R^{2}\right.$ adjusted=0.22), with 8 significant variables. In order of effect size, this included isolating self ( $\beta=.22 ; P<.001)$, getting professional help $(\beta=.20 ; P<.001)$, doing nothing $(\beta=.12 ; P<.001)$, increasing alcohol and other drug use $(\beta=.08 ; P<.001)$, sleeping too much or too little $(\beta=.07$; $P=.002)$, becoming aggressive $(\beta=.05 ; P=.015)$, taking more risks $(\beta=.05 ; P=.027)$, and working less or working more $(\beta=.04 ; P=.036)$. 
Table 5. Linear regression of coping responses after experiencing a stressful transitional life event as predictors of suicidal thoughts and behaviors by sex.

\begin{tabular}{|c|c|c|c|c|}
\hline Variable & Linear regression $(t)$ & $P$ value & $\beta$ & $95 \% \mathrm{CI}$ \\
\hline \multicolumn{5}{|l|}{$\mathrm{STB}^{\mathrm{a}}$ in men } \\
\hline Became aggressive & 2.87 & .004 & .09 & 0.04 to 0.19 \\
\hline Bossy or inflexible or angry & -0.72 & .47 & -.02 & -0.09 to 0.04 \\
\hline Eat more or less & 1.61 & .11 & .05 & -0.01 to 0.11 \\
\hline Spiritual activity & -1.78 & .08 & -.05 & -0.12 to 0.01 \\
\hline Got professional help & 6.10 & $<.001$ & .20 & 0.14 to 0.27 \\
\hline Increased tobacco or alcohol or drugs & 2.10 & .036 & .06 & 0.00 to 0.13 \\
\hline Isolated self & 6.38 & $<.001$ & .21 & 0.15 to 0.28 \\
\hline Overdo activities & -0.56 & .55 & -.02 & -0.09 to 0.05 \\
\hline Sleep too much or too little & 2.84 & .005 & .09 & 0.03 to 0.16 \\
\hline Spend time with friends or loved ones & -1.43 & .15 & -.04 & -0.12 to 0.02 \\
\hline Work less or more & -1.16 & .25 & -.04 & -0.10 to 0.03 \\
\hline Take more risks & 1.60 & .11 & .05 & -0.01 to 0.12 \\
\hline Talk to someone about feelings & 0.81 & .42 & .03 & -0.04 to 0.11 \\
\hline Talk to someone for advice & -0.51 & .61 & -.02 & -0.09 to 0.05 \\
\hline Do nothing & 2.90 & .004 & .09 & 0.03 to 0.17 \\
\hline Other & 1.98 & .048 & .06 & 0.00 to 0.16 \\
\hline \multicolumn{5}{|l|}{ STB in women } \\
\hline Became aggressive & 2.44 & .015 & .05 & 0.01 to 0.14 \\
\hline Bossy or inflexible or angry & 0.87 & .38 & .02 & -0.02 to 0.06 \\
\hline Eat more or less & 1.92 & .055 & .04 & 0.00 to 0.09 \\
\hline Spiritual activity & -1.48 & .14 & -.03 & -0.08 to 0.01 \\
\hline Got professional help & 8.91 & $<.001$ & .20 & 0.17 to 0.26 \\
\hline Increased tobacco or alcohol or drugs & 3.98 & $<.001$ & .08 & 0.05 to 0.14 \\
\hline Isolated self & 9.47 & $<.001$ & .22 & 0.17 to 0.27 \\
\hline Overdo activities & -1.38 & .17 & -.03 & -0.08 to 0.01 \\
\hline Sleep too much or too little & 3.06 & .002 & .07 & 0.03 to 0.13 \\
\hline Spend time with friends or loved ones & -1.55 & .12 & -.03 & -0.08 to 0.01 \\
\hline Work less or more & 2.10 & .036 & .04 & 0.00 to 0.09 \\
\hline Take more risks & 2.22 & .027 & .05 & 0.01 to 0.11 \\
\hline Talk to someone about feelings & -1.62 & .11 & -.04 & -0.10 to 0.01 \\
\hline Talk to someone for advice & -0.41 & .68 & -.01 & -0.06 to 0.04 \\
\hline Do nothing & 5.27 & $<.001$ & .12 & 0.09 to 0.19 \\
\hline Other & 1.82 & .06 & .04 & 0.00 to 0.11 \\
\hline
\end{tabular}

${ }^{\mathrm{a}} \mathrm{STB}$ : suicidal thoughts and behaviors.

\section{Discussion}

\section{Principal Findings}

This study describes an analysis of men's and women's experience of transitional life events, STB, and coping strategies, with data being gathered in the largest known international web-based survey in this area. In keeping with previous literature, the proportion of women reporting STB was significantly larger than the number of men reporting STB $[35,36]$. Following this pattern, women also reported at a significantly higher rate that the transitional life event (or events) they experienced was stressful, compared with men. These findings may suggest that the experience or the perception of stress is different between men and women, as highlighted in 
previous research [37]. Moreover, the results may indicate that women have more proactive coping strategies when faced with stressful transitional life events. This is considering the finding that women not experiencing STB were more likely to engage with their social networks when coping with life events they perceived as stressful. To some extent, this rationale supports meta-analytic research that women predominantly engage in more adaptive or expressive types of coping strategies [20]. However, in this study, there were no sex differences in reports of feeling stressed once experiencing both a transitional life event and STB. Furthermore, the sex differences in expressive style coping after a stressful transitional life event (specifically, talking to someone about feelings, spending time with friends or loved ones, and talking to someone for advice) were present when individuals were not experiencing STB but dissipated once individuals reported STB. Therefore, this study may extend previous meta-analytic findings [20]. Namely, it is possible that women articulate their perceived feelings of stress to others at an earlier stage (ie, when they are not experiencing STB), whereas men might be less likely to seek support from others until they move toward a crisis point.

The results from the logistic regression indicated that both men and women who reported experiencing a stressful transitional life event in the past 12 months had higher AOR of STB. The subsequent linear regression highlighted some potential warning signs for STB, most of which have been identified as predictors of future STB and are among the warning signs for many international guidelines [38]. This included becoming aggressive; self-isolating behavior; changes in sleep; and increased use of tobacco, alcohol, or other drugs for all participants, irrespective of their sex. For women specifically, warning signs also included increased risk taking and changes in work behaviors. Previous research has demonstrated a relationship between suicide and substance abuse [35,39], sleep disturbances [40], and social isolation [41]. This study adds to the literature by highlighting some identifiable signs that individuals experiencing STB engage in after going through a transitional life event (or events) they perceive as stressful.

These warning signs of STB, after experiencing a transitional life event, may be compounded when considering the chi-square finding that both men and women who reported STB, compared with those who did not, were significantly less likely to engage in potentially helpful coping strategies (eg, spending more time with friends and loved ones and talking to someone about one's feelings). These strategies may help buffer a person against distress. Furthermore, it was found that respondents experiencing STB reported higher rates of accessing professional help compared with those who did not report STB, and seeking professional help significantly explained the variance in STB for men and women. Despite this, more than half of all the participants with STB did not seek help. Indeed, one-third of the participants who reported STB (33.2\%) said they did nothing to cope after a stressful transitional life event. This explained the variance in STB for both sexes in the linear regression. Although research has consistently reported that men are less likely to seek help than women [42], this research found no differences in seeking professional help between men and women when experiencing STB. Notably, seeking professional help significantly explained the variance in STB in both men and women. Women, however, were more likely to seek professional help when experiencing stress but were not reporting STB. Again, this may indicate that men are waiting until they head toward a crisis point to seek help. This delay seen in men toward help seeking may be because of self-stigma, a wish to handle the problem on one's own, and a low perceived need for care [42].

Other significant findings include that a majority of sociodemographic variables that resulted in higher or lower AOR of STB — such as identifying as LGBTQIA, NEET (women only), suddenly or unexpectedly becoming unemployed (men only), living alone (women only), satisfaction with intimate bonds, satisfaction with social support, starting a new job, becoming a parent for the first time (men only), and relationship breakdown (men only) — arguably relate to an individual's level of social connectedness, or lack thereof. In the literature, social isolation and the absence of social support are established correlates of suicide risk, with O'Conner and Nock [43] suggesting that it is a vital component of contemporary models of suicidal behavior. Furthermore, the higher rates of STB among these various subgroups [44-48] could be attributed to disruptions or distress related to not only their social connectedness but also connectedness more broadly to include their job or perceived sense of purpose, which would be consistent with existing models that characterize the development of strong STB [49].

\section{Implications for Policy and Practice}

When taking all these factors together, these findings emphasize the importance of promoting more helpful coping strategies after experiencing a stressful transitional life event. For example, men were more likely to engage in maladaptive coping strategies associated with completed suicides, such as substance abuse $[35,39]$. Health services and campaigns should focus on helping men recognize and respond to life stressors earlier. This includes equipping them with the skills to identify triggers and early warning signs of stress so that they can take appropriate action, seek help, and engage in more adaptive coping strategies earlier. This is also important for women, particularly given the finding that increased use of tobacco, alcohol, or other drugs was associated with STB for women only. Overall, a greater understanding in the community of these potential warning signs of STB in people who have experienced a stressful transitional life event might also improve the identification, response, and provision of support.

In addition, in accordance with other Australian research recommendations [50], enhancing social connectedness in the general community is crucial, particularly given the findings that isolating oneself as a coping strategy after experiencing a stressful transitional life event explained variance in STB for both men and women. Additional focus should also be placed on supporting and tailoring services to meet the needs of more vulnerable groups highlighted in this research, such as young people, people who identify as LGBTQIA, people experiencing employment-related concerns, people with lower satisfaction toward their social support and intimate bonds, men who experience relationship breakdown, and women who live alone. 
Overall, interventions that target improving community support and social connectedness should be considered in health services, educational institutions, and workplace settings, particularly after someone experiences a stressful transitional life event. Research suggests that augmentation of social connectedness through not only traditional face-to-face methods but also digital mental health supports should be considered [50,51], particularly given that these can improve access for more socially isolated individuals [52].

\section{Strengths and Limitations}

A key strength of this study is that it is one of the largest samples to date, providing data on transitional life events, coping strategies, and multiple factors related to suicide risk. It is, however, not without limitations-many of which are outlined in the main reports' executive summary, including the nonepidemiological nature of web-based research that holds the potential for avidity and internet bias [21]. Indeed, in this study, suicidal thoughts were common, with $23.8 \%$ of the total sample having thought about taking their own life in the past 12 months. Furthermore, suicide plans and attempts over the past 12 months were reported by $7.8 \%$ and $3.0 \%$ of the respondents, respectively. These rates are far higher than those reported in the literature, with the World Health Organization's 12-month prevalence estimates being at $2.0 \%$ for suicidal thoughts, $0.6 \%$ for plans, and $0.3 \%$ for attempts within developed countries [53]. It is also possible that those with a greater interest in the subject matter were more likely to participate in this research. This research still provides valuable insights as the interactions between variables, not merely the statistical frequencies, provide meaningful information. However, a selection bias could mean that the findings relating to associations between life events, coping mechanisms, and STB may be more specific to higher risk groups. For this reason, we also did not compare differences across countries, although countries presented similar sociodemographics (Multimedia Appendix 2).

Additional limitations of this substudy are as follows. First, the brief screener for STB via the PSFS relies on binary responses and, thus, may be less sensitive to subtle response variances. Second, known predictors of suicide, such as mental ill health, alcohol, and/or other substance misuse [38], were also not considered in the multinomial regression, as we focused on sociodemographic factors. It is acknowledged that their inclusion would influence the results. Furthermore, only 7 transitional life events were considered in the Global Health \& Wellbeing Survey. Other transitional life events may warrant further research (such as commencing a long-term relationship, getting married, and death of a loved one); however, because of the sheer scale of the survey, not all transitional life events could be included. In addition, some transitional life events, specifically experiencing a relationship breakdown and suddenly or unexpectedly becoming unemployed, are acknowledged to be far more of a negative experience than others included in this survey, which may have influenced the results. These were included, however, as they are becoming far more common in the included target countries, nearly one-fourth $(22.9 \%)$ of the entire sample had experienced a relationship breakdown in the past 12 months. The research also relied on self-report, which asked participants to recall the transitional life events experienced and STB over the past 12 months. This lengthy recall period is a common issue in research [6]. Interview-based approaches instead of self-report checklists may allow for greater resolution in the dating of an event and provide further depth of assessment in the relationship between stressors and STB [6]. However, interview-based research has also been shown to limit the disclosure of sensitive items compared with web-based approaches, particularly for men and people not in education, training, or employment [54]. Thus, the web-based survey approach used in this study may allow for a greater level of disclosure of sensitive information, such as STB.

\section{Conclusions}

Although nonepidemiological in nature, the considerable size of the Global Health \& Wellbeing Survey provides some key insights into the international landscape for men and women, with good representation from minority subpopulations. Multifaceted approaches toward providing support to individuals experiencing STB after experiencing a stressful transitional life event is crucial. Essential to this includes risk mitigation through systematic identification and assessment [55] and a greater emphasis on health promoting behaviors and coping mechanisms within communities to strengthen resilience. When designing interventions, services should consider using sex-specific or targeted strategies to inform both the early identification of warning signs relating to STB and the provision of effective early intervention to mitigate the immediate risk and long-term impact of STB [56]. Beyond traditional interventions, these results show that enhancing social connectedness and reducing marginalization may be vital. This is especially relevant for groups at risk of marginalization, including those who had lower satisfaction with their social support and intimate bonds and specific populations, such as young people, people who identify as LGBTQIA, and have employment-related issues.

\section{Acknowledgments}

The Global Health \& Wellbeing Survey was commissioned by the Movember Foundation and conducted by the University of Sydney's Brain and Mind Centre and the Young and Well Cooperative Research Centre (Young and Well CRC: 2011-2016). The authors would like to acknowledge the respondents who provided consent to participate on the web in the Global Health \& Wellbeing Survey; the International Consortia for the Global Health \& Wellbeing Survey, including Professor Sagar Parikh, Professor Richard Porter, Professor Jan Scott, and Dr Michael Rovito; the Movember Foundation (Australia) lead on the project Therese Fitzpatrick; and the Brain and Mind Center team: Hannah Yee, Victoria Baldwin, Lisa Whittle, Django White, Laura Ospina Pinillos, and Sarah Piper. The Movember Foundation provided the funding for this study. The authors would also like to acknowledge the National Health and Medical Research Council for funding the YOUTHe Centre of Research Excellence for reducing suicidal thoughts and behaviors in young people presenting for health care (GNT1171910). 


\section{Conflicts of Interest}

IH was an inaugural commissioner on Australia's National Mental Health Commission (2012-2018). He is the Co-Director, Health and Policy, at the Brain and Mind Centre (BMC), University of Sydney. The BMC operates early intervention youth services at Camperdown under contract to headspace. IH has previously supported community-based and pharmaceutical industry-supported (Wyeth, Eli Lily, Servier, Pfizer, and AstraZeneca) projects focused on the identification and better management of anxiety and depression. He was a member of the Medical Advisory Panel for Medibank Private until October 2017, a Board Member of Psychosis Australia Trust, and a member of the Veterans Mental Health Clinical Reference Group. He is the Chief Scientific Advisor to and an equity shareholder in InnoWell. InnoWell has been formed by the University of Sydney and PricewaterhouseCoopers to deliver the Aus \$30 (US \$22.20) million Australian Government-funded Project Synergy. Project Synergy is a 3-year program for the transformation of mental health services through the use of innovative technologies. JB is the Chair of the National Advisory Council for Open Arms, Veterans, and Families Counselling Service. She is a well-being and digital health consultant to Bupa, a member of the Veterans Mental Health Clinical Reference Group, and a Chief Investigator and author of the Defense and Veterans Transition and Wellbeing Study. She is the founder of and an equity shareholder in InnoWell. She is a Professor at the Social Innovation and Chair of the Centre for Mental Health at Swinburne University and Adjunct Professor of Social Impact and Entrepreneurship at Royal Melbourne Institute of Technology. The other authors have no conflicts of interest to declare.

\section{Multimedia Appendix 1}

Participant socio-demographics for the full sample and by sex.

[DOCX File, 32 KB-Multimedia Appendix 1]

\section{Multimedia Appendix 2}

Participant socio-demographics by country.

[DOCX File, 19 KB-Multimedia Appendix 2]

\section{Multimedia Appendix 3}

Frequency and experience of suicidal thoughts and behaviours.

[DOCX File, 18 KB-Multimedia Appendix 3]

\section{Multimedia Appendix 4}

Odds and adjusted odds ratios for men and women's self-reported suicidal thoughts and behaviors by sociodemographic variables including social connection and transitional life events (Men $n=2667$; Women $n=3826$ ).

[DOCX File, 17 KB-Multimedia Appendix 4]

\section{Multimedia Appendix 5}

Frequency of men and women's responses based on stressful transitional life event experience for participants who did and did not report suicidal thoughts and behaviours (PSFS).

[DOCX File, $20 \mathrm{~KB}-$ Multimedia Appendix 5]

\section{References}

1. Bertolote M, Fleischmann A. A global perspective in the epidemiology of suicide. Suicid 2015 Jun 11;7(2):6-8. [doi: $10.5617 /$ suicidologi.2330]

2. Klonsky ED, May AM, Saffer BY. Suicide, suicide attempts, and suicidal ideation. Annu Rev Clin Psychol 2016;12:307-330. [doi: 10.1146/annurev-clinpsy-021815-093204] [Medline: 26772209]

3. Nock MK, Borges G, Bromet EJ, Alonso J, Angermeyer M, Beautrais A, et al. Cross-national prevalence and risk factors for suicidal ideation, plans and attempts. Br J Psychiatry 2008 Feb;192(2):98-105 [FREE Full text] [doi: 10.1192/bjp.bp.107.040113] [Medline: 18245022]

4. Nock MK, Borges G, Bromet EJ, Cha CB, Kessler RC, Lee S. Suicide and suicidal behavior. Epidemiol Rev 2008;30:133-154 [FREE Full text] [doi: 10.1093/epirev/mxn002] [Medline: 18653727]

5. Nonfatal Hospitalized Injuries, Both Sexes, All Ages, Self-Harm, United States. Centers for Disease Control and Prevention. 2010. URL: https://wisqars.cdc.gov:8443/costT [accessed 2018-02-01]

6. Liu RT, Miller I. Life events and suicidal ideation and behavior: a systematic review. Clin Psychol Rev 2014 Apr;34(3):181-192. [doi: 10.1016/j.cpr.2014.01.006] [Medline: 24534642]

7. Värnik P. Suicide in the world. Int J Environ Res Public Health 2012 Mar;9(3):760-771 [FREE Full text] [doi: 10.3390/ijerph9030760] [Medline: 22690161] 
8. World Health Organization. Preventing Suicide: A Global Imperative. Geneva, Switzerland: World Health Organization; 2014.

9. Nock MK, Green JG, Hwang I, McLaughlin KA, Sampson NA, Zaslavsky AM, et al. Prevalence, correlates, and treatment of lifetime suicidal behavior among adolescents: results from the national comorbidity survey replication adolescent supplement. JAMA Psychiatry 2013 Mar;70(3):300-310 [FREE Full text] [doi: 10.1001/2013.jamapsychiatry.55] [Medline: 23303463]

10. Causes of Death, Australia, 2018. Australian Bureau of Statistics, Australian Government. URL: http://www.abs.gov.au/ ausstats/abs@.nsf/mf/3303.0 [accessed 2018-09-26]

11. Suicide: Facts at a Glance. Centers for Disease Control and Prevention. 2015. URL: https://www.cdc.gov/violenceprevention/ pdf/suicide-datasheet-a.pdf [accessed 2018-02-01]

12. What Do We Die From? Office For National Statistics. 2015. URL: http://www.ons.gov.uk/ons/rel/vsob1/ mortality-statistics--deaths-registered-in-england-and-wales--series-dr-/2014/sty-what-do-we-die-from.html [accessed 2018-02-01]

13. Deaths and Age-specific Mortality Rates, by Selected Grouped Causes. Statistics Canada. 2015. URL: http://www. statcan.gc.ca/tables-tableaux/sum-som/101/cst01/hlth66e-eng.htm [accessed 2018-02-01]

14. Currier D, Spittal MJ, Patton G, Pirkis J. Life stress and suicidal ideation in Australian men - cross-sectional analysis of the Australian longitudinal study on male health baseline data. BMC Public Health 2016 Oct 31;16(Suppl 3):1031 [FREE Full text] [doi: 10.1186/s12889-016-3702-9] [Medline: 28185591]

15. White VB, Leib JR, Farmer JM, Biesecker BB. Exploration of transitional life events in individuals with Friedreich ataxia: implications for genetic counseling. Behav Brain Funct 2010 Oct 27;6:65 [FREE Full text] [doi: 10.1186/1744-9081-6-65] [Medline: 20979606]

16. Kralik D, Visentin K, van Loon A. Transition: a literature review. J Adv Nurs 2006 Aug;55(3):320-329. [doi: 10.1111/j.1365-2648.2006.03899.x] [Medline: $\underline{16866826}$ ]

17. Lenz B. The transition from adolescence to young adulthood: a theoretical perspective. J Sch Nurs 2001 Dec;17(6):300-306. [doi: 10.1177/10598405010170060401] [Medline: 11804406 ]

18. Kirby R, Shakespeare-Finch J, Palk G. Adaptive and maladaptive coping strategies predict posttrauma outcomes in ambulance personnel. Traumatology 2011;17(4):25-34. [doi: 10.1177/1534765610395623]

19. Zuckerman M, Gagne M. The COPE revised: proposing a 5-factor model of coping strategies. J Res Pers 2003 Jun;37(3):169-204. [doi: 10.1016/s0092-6566(02)00563-9]

20. Tamres LK, Janicki D, Helgeson VS. Sex differences in coping behavior: a meta-analytic review and an examination of relative coping. Pers Soc Psychol Rev 2016 Dec 21;6(1):2-30. [doi: 10.1207/s15327957pspr0601_1]

21. Burns J, Davenport T, Milton A, Hickie I, Baldwin V, Ellis L. Global Health \& Well-Being Survey. Movember. 2016. URL: https://cdn.movember.com/uploads/files/Our\%20Work/GlobalHealthWellbeingSurvey ExecutiveSummary.pdf [accessed 2018-02-01]

22. Milton AC, la Monica H, Dowling M, Yee H, Davenport T, Braunstein K, et al. Gambling and the role of resilience in an international online sample of current and ex-serving military personnel as compared to the general population. J Gambl Stud 2020 Jun;36(2):477-498. [doi: 10.1007/s10899-019-09900-w] [Medline: 31620927]

23. Close S, Smaldone A, Fennoy I, Reame N, Grey M. Using information technology and social networking for recruitment of research participants: experience from an exploratory study of pediatric Klinefelter syndrome. J Med Internet Res 2013 Mar 19;15(3):e48 [FREE Full text] [doi: 10.2196/jmir.2286] [Medline: 23512442]

24. Merolli M, Gray K, Martin-Sanchez F. Therapeutic affordances of social media: emergent themes from a global online survey of people with chronic pain. J Med Internet Res 2014 Dec 22;16(12):e284 [FREE Full text] [doi: 10.2196/jmir.3494] [Medline: 25533453]

25. Bhutta CB. Not by the book: Facebook as a sampling frame. Sociol Methods Res 2012 Mar 21;41(1):57-88. [doi: 10.1177/0049124112440795]

26. Biernacki P, Waldorf D. Snowball sampling: problems and techniques of chain referral sampling. Sociol Methods Res 1981;10(2):141-163 [FREE Full text] [doi: 10.1177/004912418101000205]

27. Schuster TL, Kessler RC, Aseltine RH. Supportive interactions, negative interactions, and depressed mood. Am J Community Psychol 1990 Jun;18(3):423-438. [doi: 10.1007/BF00938116] [Medline: 2264558]

28. Wilhelm K, Parker G. The development of a measure of intimate bonds. Psychol Med 1988 Feb;18(1):225-234. [doi: 10.1017/s0033291700002051] [Medline: 3363041]

29. Lindelow M, Hardy R, Rodgers B. Development of a scale to measure symptoms of anxiety and depression in the general UK population: the psychiatric symptom frequency scale. J Epidemiol Community Health 1997 Oct;51(5):549-557 [FREE Full text] [doi: 10.1136/jech.51.5.549] [Medline: $\underline{9425466]}$

30. Jorm AF, Korten AE, Rodgers B, Jacomb PA, Christensen H. Sexual orientation and mental health: results from a community survey of young and middle-aged adults. Br J Psychiatry 2002 May;180:423-427. [doi: 10.1192/bjp.180.5.423] [Medline: 11983639]

31. Christensen H, Batterham PJ, Soubelet A, Mackinnon AJ. A test of the interpersonal theory of suicide in a large community-based cohort. J Affect Disord 2013 Jan 25;144(3):225-234. [doi: 10.1016/j.jad.2012.07.002] [Medline: 22862889] 
32. Burr EM, Rahm-Knigge RL, Conner BT. The differentiating role of state and trait hopelessness in suicidal ideation and suicide attempt. Arch Suicide Res 2018;22(3):510-517. [doi: 10.1080/13811118.2017.1366960] [Medline: 28854122]

33. Fairweather-Schmidt A, Batterham P, Butterworth P, Nada-Raja S. The impact of suicidality on health-related quality of life: a latent growth curve analysis of community-based data. J Affect Disord 2016 Oct;203:14-21. [doi: 10.1016/j.jad.2016.05.067] [Medline: 27285722]

34. Milton AC, Gill BA, Davenport TA, Dowling M, Burns JM, Hickie IB. Sexting, web-based risks, and safety in two representative national samples of young Australians: prevalence, perspectives, and predictors. JMIR Ment Health 2019 Jun 17;6(6):e13338 [FREE Full text] [doi: 10.2196/13338] [Medline: $\underline{\text { 31210139] }}$

35. Callanan VJ, Davis MS. Gender differences in suicide methods. Soc Psychiatry Psychiatr Epidemiol 2012 Jun;47(6):857-869. [doi: 10.1007/s00127-011-0393-5] [Medline: 21604180]

36. Crosby AE, Han B, Ortega LA, Parks SE, Gfroerer J, Centers for Disease Control and Prevention (CDC). Suicidal thoughts and behaviors among adults aged $\geq 18$ years--United States, 2008-2009. MMWR Surveill Summ 2011 Oct 21;60(13):1-22 [FREE Full text] [Medline: 22012169]

37. Matud M. Gender differences in stress and coping styles. Pers Individ Differ 2004 Nov;37(7):1401-1415. [doi: 10.1016/j.paid.2004.01.010]

38. Franklin JC, Ribeiro JD, Fox KR, Bentley KH, Kleiman EM, Huang X, et al. Risk factors for suicidal thoughts and behaviors: a meta-analysis of 50 years of research. Psychol Bull 2017 Feb;143(2):187-232. [doi: 10.1037/bul0000084] [Medline: 27841450]

39. Pompili M, Serafini G, Innamorati M, Biondi M, Siracusano A, di Giannantonio M, et al. Substance abuse and suicide risk among adolescents. Eur Arch Psychiatry Clin Neurosci 2012 Jan 31:- epub ahead of print. [doi: 10.1007/s00406-012-0292-0] [Medline: 22290639]

40. Goldstein TR, Bridge JA, Brent DA. Sleep disturbance preceding completed suicide in adolescents. J Consult Clin Psychol 2008 Feb;76(1):84-91 [FREE Full text] [doi: 10.1037/0022-006X.76.1.84] [Medline: 18229986]

41. Leigh-Hunt N, Bagguley D, Bash K, Turner V, Turnbull S, Valtorta N, et al. An overview of systematic reviews on the public health consequences of social isolation and loneliness. Public Health 2017 Nov;152:157-171. [doi: 10.1016/j.puhe.2017.07.035] [Medline: 28915435]

42. Yousaf O, Grunfeld EA, Hunter MS. A systematic review of the factors associated with delays in medical and psychological help-seeking among men. Health Psychol Rev 2015;9(2):264-276. [doi: 10.1080/17437199.2013.840954] [Medline:

26209212]

43. O'Connor RC, Nock MK. The psychology of suicidal behaviour. Lancet Psychiatry 2014 Jun;1(1):73-85. [doi: 10.1016/s2215-0366(14)70222-6]

44. Coker TR, Austin SB, Schuster MA. The health and health care of lesbian, gay, and bisexual adolescents. Annu Rev Public Health 2010;31:457-477. [doi: 10.1146/annurev.publhealth.012809.103636] [Medline: 20070195]

45. Kokkevi A, Rotsika V, Arapaki A, Richardson C. Adolescents' self-reported suicide attempts, self-harm thoughts and their correlates across 17 European countries. J Child Psychol Psychiatry 2012 Apr;53(4):381-389. [doi: 10.1111/j.1469-7610.2011.02457.x] [Medline: 21895649]

46. Milner A, Page A, LaMontagne AD. Long-term unemployment and suicide: a systematic review and meta-analysis. PLoS One 2013;8(1):e51333 [FREE Full text] [doi: 10.1371/journal.pone.0051333] [Medline: 23341881]

47. Milner A, Page A, LaMontagne AD. Cause and effect in studies on unemployment, mental health and suicide: a meta-analytic and conceptual review. Psychol Med 2014 Apr;44(5):909-917. [doi: 10.1017/S0033291713001621] [Medline: 23834819]

48. Milner A, Witt K, LaMontagne AD, Niedhammer I. Authors' reply: 'response to: 'psychosocial job stressors and suicidality: a meta-analysis and systematic review' by Milner. Occup Environ Med 2018 Apr;75(4):318. [doi: 10.1136/oemed-2018-104997] [Medline: 29374625]

49. Klonsky ED, May AM. The three-step theory (3ST): a new theory of suicide rooted in the 'ideation-to-action' framework. Int J Cogn Ther 2015 Jun;8(2):114-129. [doi: 10.1521/ijct.2015.8.2.114]

50. Page A, Atkinson J, Campos W, Heffernan M, Ferdousi S, Power A, et al. A decision support tool to inform local suicide prevention activity in Greater Western Sydney (Australia). Aust N Z J Psychiatry 2018 Oct;52(10):983-993. [doi: 10.1177/0004867418767315] [Medline: 29671335]

51. Rice S, Robinson J, Bendall S, Hetrick S, Cox G, Bailey E, et al. Online and social media suicide prevention interventions for young people: a focus on implementation and moderation. J Can Acad Child Adolesc Psychiatry 2016;25(2):80-86. [Medline: 27274743]

52. Chen YR, Schulz PJ. The effect of information communication technology interventions on reducing social isolation in the elderly: a systematic review. J Med Internet Res 2016 Jan 28;18(1):e18 [FREE Full text] [doi: 10.2196/jmir.4596] [Medline: 26822073]

53. Borges G, Nock MK, Abad JM, Hwang I, Sampson NA, Alonso J, et al. Twelve-month prevalence of and risk factors for suicide attempts in the World Health Organization World Mental Health Surveys. J Clin Psychiatry 2010 Dec;71(12):1617-1628 [FREE Full text] [doi: 10.4088/JCP.08m04967blu] [Medline: 20816034] 
54. Milton AC, Ellis LA, Davenport TA, Burns JM, Hickie IB. Comparison of self-reported telephone interviewing and web-based survey responses: findings from the second Australian young and well national survey. JMIR Ment Health 2017 Sep 26;4(3):e37 [FREE Full text] [doi: 10.2196/mental.8222] [Medline: 28951382]

55. Iorfino F, Davenport TA, Ospina-Pinillos L, Hermens DF, Cross S, Burns J, et al. Using new and emerging technologies to identify and respond to suicidality among help-seeking young people: a cross-sectional study. J Med Internet Res 2017 Jul 12;19(7):e247 [FREE Full text] [doi: 10.2196/jmir.7897] [Medline: 28701290]

56. Iorfino F, Hermens DF, Cross SP, Zmicerevska N, Nichles A, Groot J, et al. Prior suicide attempts predict worse clinical and functional outcomes in young people attending a mental health service. J Affect Disord 2018 Oct 1;238:563-569. [doi: 10.1016/j.jad.2018.06.032] [Medline: 29940520]

\author{
Abbreviations \\ AOR: adjusted odds ratio \\ BMC: Brain and Mind Centre \\ EET: in education, employment, or training \\ LBOTE: language background other than English \\ LGBTQIA: lesbian, gay, bisexual, transsexual, queer, intersex, or asexual \\ NEET: not in education, employment, or training \\ PSFS: Psychiatric Symptom Frequency Scale \\ STB: suicidal thoughts and behaviors
}

\author{
Edited by G Strudwick; submitted 23.02.20; peer-reviewed by M Iseselo, K Aguirre; comments to author 19.04.20; revised version \\ received 05.05.20; accepted 12.06.20; published 11.09 .20 \\ Please cite as: \\ Milton AC, Davenport TA, Iorfino F, Flego A, Burns JM, Hickie IB \\ Suicidal Thoughts and Behaviors and Their Associations With Transitional Life Events in Men and Women: Findings From an \\ International Web-Based Sample \\ JMIR Ment Health 2020;7(9):e18383 \\ URL: http://mental.jmir.org/2020/9/e18383/ \\ doi: $10.2196 / 18383$ \\ PMID: 32915160
}

(C)Alyssa Clare Milton, Tracey A Davenport, Frank Iorfino, Anna Flego, Jane M Burns, Ian B Hickie. Originally published in JMIR Mental Health (http://mental.jmir.org), 11.09.2020. This is an open-access article distributed under the terms of the Creative Commons Attribution License (https://creativecommons.org/licenses/by/4.0/), which permits unrestricted use, distribution, and reproduction in any medium, provided the original work, first published in JMIR Mental Health, is properly cited. The complete bibliographic information, a link to the original publication on http://mental.jmir.org/, as well as this copyright and license information must be included. 